\title{
Physicians' nutritional counselling practices: A study in district hospitals of Chhattisgarh
}

Introduction: Nutrition counseling is an important tool for fostering healthy nutrition behavior among individuals. Physicians play a strategic role in imparting nutrition advice to their patient during daily encounters in healthcare settings. Present study explored nutritional counseling practices and attitudes of physicians working at district hospitals in Chhattisgarh state in India. Materials and Methods: A cross-sectional study was conducted to explore present scenario of nutritional counseling practices by Physicians from $1^{\text {st }}$ April to $30^{\text {th }}$ June 2011. Questionnaires and observation guides were framed based on previous studies. Both 3-point and 5-point Likert scale were used to explore the knowledge, satisfaction, and attitude related statements. Results: Majority of the respondents (76\%) were strongly in favor of training in nutrition counseling and $35 \%$ believed that they should spend more time exploring dietary habit of patients in routine practice. Fifty-four percent of practitioners were of the opinion that counseling is futile and $62 \%$ considered counseling as time-consuming process. Majority of physician expressed their willingness to undergo additional training in nutrition. Discussion: In view of emerging burden of chronic disease related to nutrition and life style, it is imperative that physician should be trained adequately so as to advice their patients appropriately, pertaining to nutrition.

Key words: Chhattisgarh, nutrition counseling, physician, primary care practice

\section{Ashish Sharma, Sanghamitra Pati ${ }^{1}$, Nayan Chakravarty ${ }^{1}$, Abhimanyu S. Chauhan' \\ Department of Health Services, Medical Officer, Government of Odisha, ${ }^{1}$ Academics, Indian Institute of Public Health, \\ Bhubaneswar, Odisha, India}

Address for the Correspondence: Mr. Abhimanyu Singh Chauhan, JSS Software Technology Park, $2^{\text {nd }}$ and $3^{\text {rd }}$ Floor, E1/1, Infocity Road, Patia, Bhubaneswar, Orissa, India. E-mail: abhimanyu.hm@gmail.

com

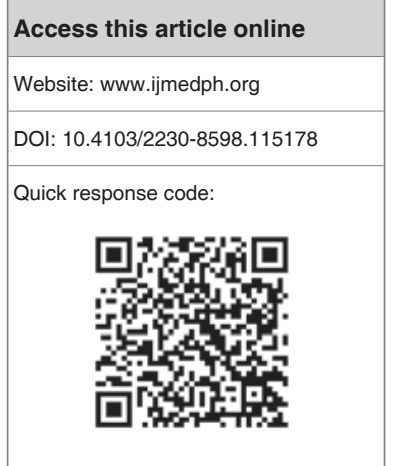

\section{INTRODUCTION}

Nutrition is the science of food and its relationship to health; it is concerned primarily with the part played by the nutrients in the body growth, the development and the maintenance. ${ }^{[1]}$ Nutrition is a critical part of health and development. Better nutrition is related to improved health, stronger immune system, safer pregnancy and child birth, lower risk of non-communicable diseases and longevity. The role of nutrition in both healthy and non-healthy situation is also quite well known.

Nutritional imbalance is on rise worldwide, including India, resulting in emergence of various diseases. There are some evidences of emerging nutritional transitions in India, as well as worldwide due to rising urbanization, industrialization and the changes in the economic status of the population. ${ }^{[2]}$ Migration and resettlement of people are also considered to be one of the causes for rising of the nutrition related non communicable diseases. Several studies and publications shows that the rising incidence of obesity, is posing treat to the population to almost equal scale to that of under-nutrition. Under-nutrition continues to be a major problem but the prevalence of over nutrition is emerging as a significant problem; especially in urban areas. The prevalence of obesity has been found higher among the women $(10.9 \%)$ compared to that of men $(7.8 \%)$ in rural areas. ${ }^{[3]}$ Protein energy malnutrition (PEM), micronutrient deficiencies such as vitamin A deficiency (VAD), iron deficiency anemia (IDA), iodine deficiency disorders (IDD) and vitamin B complex deficiency are the nutrition problems frequently encountered, particularly among the rural, poor and urban slum communities. ${ }^{[4]}$ There is an increasing trend in prevalence of the other life style or nutrition related diseases such as hypertension, diabetes mellitus, and cardio-vascular diseases etc., contributing to rising trends in the mortality and the morbidity of NR-NCDs. ${ }^{[5]}$

People's perceptions of the food and the dietary behavior has been affected greatly as there has been a shift from the traditional foods to the modern foods, changing the cooking practices, increased use of the processed and ready to eat foods, intensive marketing of the junk foods and the beverages. 
Multiple sources of the health and nutrition related information misleads and confuse the people unnecessarily and influence the dietary behavior. ${ }^{[6]}$ In this context, counseling related to food and the dietary behavior can play a big role.

However, nutrition related behaviors are the most neglected in clinical. ${ }^{[7]}$ Nutritional counseling can be understood as a combination of the nutrition expertize and the psychological skill delivered by a trained nutrition counselor who under stands how to work within the current medical setting and is being done by the Physicians, Dieticians, and the Nutritionists etc. ${ }^{[8]}$ Nutritional counseling is a type of assessment made by which by a counselor has to analyze various health needs regarding the diets and the physical exercises. Thus, Nutritional counseling is an ongoing process in which a health professional, usually a doctor, deals with an individual to assess his or her usual dietary intake and identify areas where the change is needed. In the society, the Physicians are believed to be the best advisor/counselor for any of the health related issues and are the most trusted. The goal of nutritional counseling is to help a person to make and maintain the dietary changes. Such an assessment is beneficial to the people and can help those with the diseases and or the disorders. However, studies have reported that, there is limited nutritional counseling by physician in their day to day clinical practice. Therefore, present study was undertaken to explore the existing system for nutritional counseling, practices, attitudes and behaviors of physicians in secondary care level hospitals and to find the gap between policy and practice. The proposed study has been carried out in the state of Chhattisgarh, India.

\section{MATERIALS AND METHODS}

A cross-sectional study was conducted to explore present scenario of nutritional counseling practices by Physicians from $1^{\text {st }}$ April to $30^{\mathrm{Th}}$ June 2011. The study was undertaken across 5 randomly selected district hospitals (Raipur, Durg, Korba, Janjgir and Rajnandgaon) out of 16 district hospitals in the state of Chhattisgarh, India. Both allopathic and AYUSH stream doctors (denoted as Physician in this study) working in the district hospitals dealing with both in-patients and out-patients were considered. All general physicians (GP), who were willing to participate in this study, were included after seeking a written consent from them. Out of 58 physicians available during the study period 37 GPs gave their consent and were included in the study. Additionally, 25 in-patient and 35 out-patients were randomly selected, either from Medicine or General OPD across all the five selected district hospitals after seeking proper consent from the participating patients. The patients were interviewed in detail to explore physicians' nutritional counseling practices. Surgically intervened patients and patients less than 1 day ( $24 \mathrm{~h}$ ) of stay were excluded from the study.

All the study tools were developed and field tested in a non-study hospital, before actual administering. Some minor modification in study tools were undertaken after pilot testing. Questionnaires and observation guides were framed based on previous studies. ${ }^{[9]}$ Semi-structured questionnaire was used to gather information on
GPs knowledge, behaviors, attitude and practices in nutrition counseling. Both 3-point and 5-point Likert scale were used to explore the knowledge, satisfaction, and attitude related statements. Similarly, semi-structured questionnaire were used for both in-patient and out-patient interviews, which accounted for patients experiences, their satisfaction regarding nutritional counseling on a 5-point Likert scale. Observation guides were used for direct observation of nutritional counseling practices for both in and out-patient departments. In every district hospital, physicians-patients encounters in OPD were studied in-depth to understand the physician-patient communication processes pertaining to nutritional counseling.

\section{Ethical consideration}

The study was approved by the Institutional Committee as a partial fulfillment towards post-graduate diploma in public health management at IIPH-Bhubaneswar. Permission was taken from The Directorate Health and Family Welfare, Govt. of Chhattisgarh and Civil Surgeons of the concerned district hospitals to conduct the study after briefing them about the study. A written consent on consent forms were taken before proceeding for an interview. Authors gratefully acknowledge the support of Ministry of Health and Family Welfare, Government of Chhattisgarh, towards sponsoring the PGDPHM program. We are deeply indebted to all the physicians and patients for their participation in this study.

\section{RESULTS}

All the 37 study physicians completed the self-administered semi-structured questionnaire. Upon being asked to calculate body mass index (BMI), it was observed that $4(11 \%)$ of physicians were able to calculate, while rest were unable to do so [Figure 1]. Seventy-eight percent of GPs were of the opinion that lack of knowledge innutrition is one of the barriers, in providing nutritional advice to their patients [Figure 2].

All the interviewed physicians were found to impart some form of nutritional advice to their patients. Among them 84\% physicians were satisfied with their nutritional counseling process; however $70 \%$ physicians expressed their concerns regarding lack of time, poor

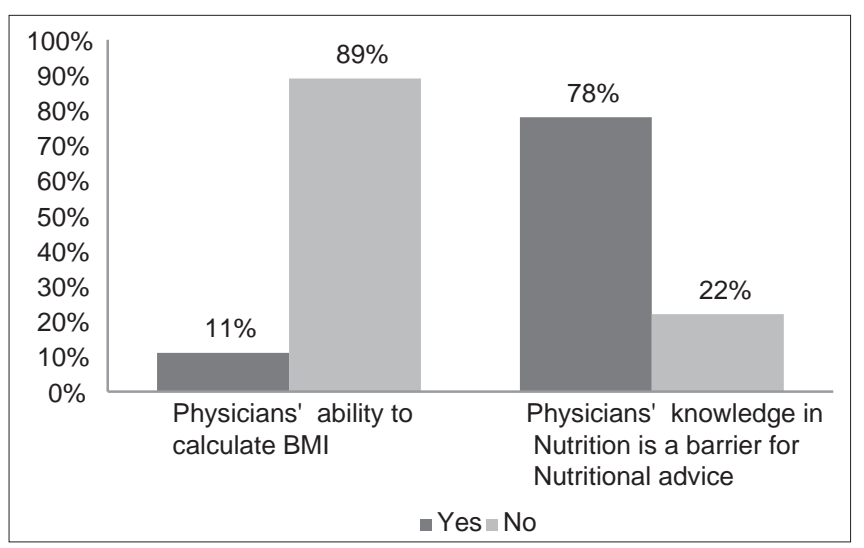

Figure 1: Physicians' knowledge in nutrition 
remuneration for counseling, poor patient compliance, physician's inability to identify patients who could benefit from counseling, physician's own counseling skill and knowledge in nutrition as the common barriers to impart nutritional counseling to their patients. One of the respondent physicians stated that lack of guidelines or protocol in clinical nutrition is also a barrier for good nutritional counseling.

When asked about their perception and attitude on nutritional counseling, $54 \%$ of practitioners were of the opinion that counseling is a waste of time because people do not change their habits anyway. More so, $62 \%$ of the physician considers counseling as a time intensive process as patients tend to ask too many questions. Almost half the participants believed eating to be a pleasurable activity and therefore convincing patients on nutritional benefits becomes difficult [Table 1].

Majority of the respondents $(76 \%)$ were strongly in favor of training in nutrition counseling; whereas, $35 \%$ of the physicians strongly believed that they should spend more time exploring dietary habit of patients in routine practice. All the respondents supported training of physicians in nutrition counseling, role of nutrition counseling in changing patient behavior and exploring dietary habits of patients as important [Table 1].
In comparison to physicians' satisfaction to their own nutritional counseling, the opinion among patients (both in-door and out-patients) was found to be different. More than half (54\%) of in-patients were not satisfied with their doctors' advice regarding nutrition. Whereas, 20\% out-patients were satisfied with the nutritional advice they received from their physicians [Figure 3].

\section{DISCUSSION}

Poor diet is a key risk factor contributing to a large portion of the world's disease burden. There has been a significant change in the dietary habits and the physical activity levels worldwide, as a result of the industrialization, urbanization, economic development and the food market globalization. ${ }^{[10]}$ The world is facing a double burden of the diseases due to the increase in prevalence of malnutrition (Over nutrition and under nutrition) and the non-communicable chronic diseases with a great increase in both the morbidity and the mortality. There are also significant proportion of malnutrition, obesity, hypertension, cardiovascular diseases etc., in India. ${ }^{[11]}$

Nutrition and nutrition counseling is not something alien to Indian society. However, necessity of nutritional counseling is yet to be recognized within the public health system in India. Nutritional counseling is expected to be the job of physicians. Physicians are

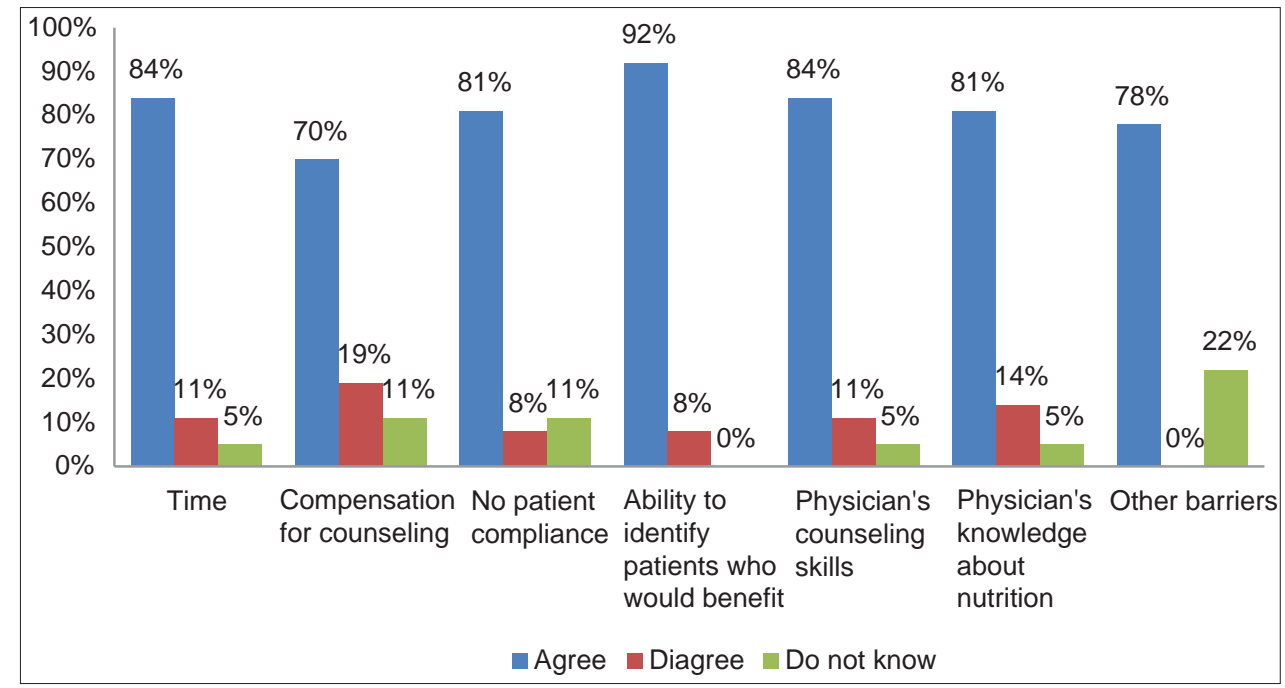

Figure 2: Physicians' barrier to provide nutritional counseling

\begin{tabular}{|c|c|c|c|c|c|}
\hline Item & $\begin{array}{c}\text { Strongly disagree } \\
(\%)\end{array}$ & $\begin{array}{c}\text { Somewhat disagree } \\
(\%)\end{array}$ & $\begin{array}{l}\text { Neutral } \\
(\%)\end{array}$ & $\begin{array}{c}\text { Somewhat agree } \\
(\%)\end{array}$ & $\begin{array}{l}\text { Strongly } \\
\text { agree (\%) }\end{array}$ \\
\hline Patients ask so many questions & $0(0)$ & $2(6)$ & $12(32)$ & $18(49)$ & $5(13)$ \\
\hline $\begin{array}{l}\text { Pleasure of eating is more important } \\
\text { than it's benefit }\end{array}$ & $2(6)$ & $2(6)$ & $15(40)$ & $12(32)$ & $6(16)$ \\
\hline Counseling is a waste of time & $0(0)$ & $2(6)$ & $12(32)$ & $18(49)$ & $5(13)$ \\
\hline $\begin{array}{l}\text { Training of physician in human } \\
\text { nutrition and counseling is required }\end{array}$ & $0(0)$ & $0(0)$ & $2(5)$ & $7(19)$ & $28(76)$ \\
\hline $\begin{array}{l}\text { Nutritional counseling in the practice is } \\
\text { effective at changing patients behavior }\end{array}$ & $0(0)$ & $0(0)$ & $2(5)$ & $17(46)$ & $18(49)$ \\
\hline $\begin{array}{l}\text { Physician should spend more time } \\
\text { exploring dietary habits of patients }\end{array}$ & $0(0)$ & $0(0)$ & $8(22)$ & $16(43)$ & $13(35)$ \\
\hline
\end{tabular}




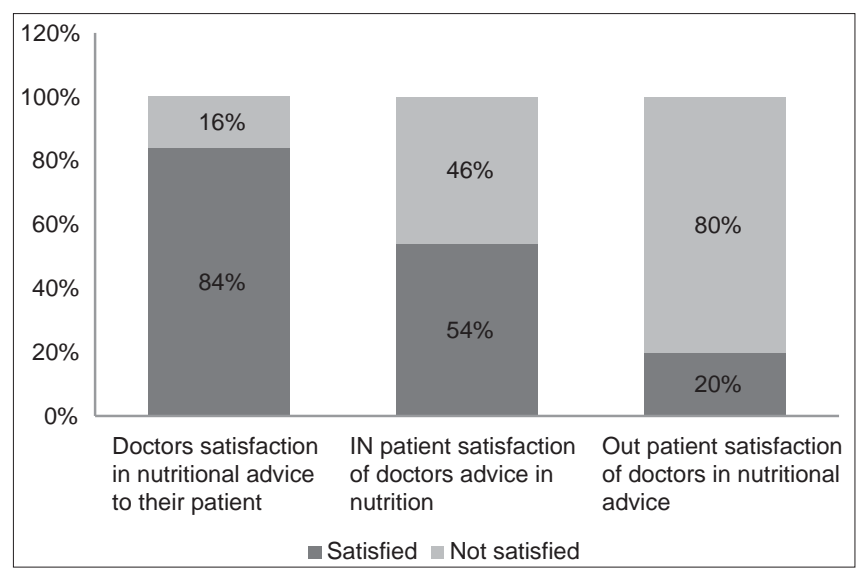

Figure 3: Satisfaction levels of doctors' and patients' (both in- and out-patients) in nutritional counseling

in a unique place to provide guidance and counseling to patients as they are the primary care provider and much trusted. Yet, there exist some barriers in imparting nutritional counseling by physicians. Present study attempts to explore the attitude, practices and related barriers among physicians, which may influence their nutritional counseling behavior. The study among selected district hospitals in Chhattisgarh highlights that physician's knowledge in nutrition is one of the prime barriers in providing good nutritional advice to their patients $(78 \%)$. Among other factors, more than two-thirds of the physicians agreed that lack of time, compensation for counseling, poor patient compliance, inability to identify patients who would benefit and counseling skill as the main barriers to provide nutritional counseling to their patients.

However, more than three fourth of the doctors providing counseling services are satisfied with their services whereas half of in-patients are satisfied with the advice that they are receiving from their respective counselors. The extent of dis-satisfaction has been recorded much higher for out-patients, where more than $80 \%$ of the responding patients have shown dis-satisfaction with the counseling that they are receiving from their respective physicians. This trend could be because of the high out-patient (OPD) loads and limited time, whereas physicians find more time to counsel indoor patients.

It is interesting to note that more than three-fourth of physicians recommends additional training in nutrition as continuing medical education. It is quite debatable how much these trainings on increasing the level of knowledge of nutrition would be helpful as majority of the physicians $(60 \%)$ strongly feels that counseling is a waste of time because people do not change their habits anyway. Trainings more focused towards building up their attitudes towards nutrition counseling would be more productive in this context.

Nutritional counseling has been a neglected area for years by medical and health educators because of various reasons. Although, physicians have much less time to advice but at the same time we need to consider that the physicians are much more trusted and their words are taken more seriously by patients. The time has come to consider this aspect of health care and it demands much larger and urgent attention.

\section{REFERENCES}

1. Cannon G, Leitzmann C. The new nutrition science. Public Health Nutrition 2005;8:673-94.

2. Griffiths PL, Bentley ME. The dual burden of the nutrition transition for woman in India: A comparison of the rural poor and the urban elite in Andhra Pradesh. J Nutr 2001;131:2692-700.

3. International Institute for Population Sciences. NFHS 3 Chhattisgarh. 2008. Available from: http://www.nfhsindia.org/pdf/Chhattisgarh.pdf. [Last accessed on 2011 Jun02].

4. National Institute of Nutrition. Dietary guidelines for Indians a manual. $2^{\text {nd }}$ ed. Hyderabad: National Institute of Nutrition; 2010.p. 1-126.

5. The World Health Report 2002: Reducing Risks, Promoting Healthy life. WHO; 2002. Available at: http://www.who.int/whr/2002/Overview_E. pdf [Last accessed on 2012 Feb 3].

6. Bagchi K. Nutrition programmes in India retrospect and prospect. Health Popul Perspect Issues 1981;4:223-42.

7. Kopelman P, Lennard-Jones J. Nutrition and patients: A doctor's responsibility. Clin Med 2002;2:391-4.

8. Snetselaar LG. Nutrition Counseling Skills for Medical Nutrition Therapy. Frederick, MD: Aspen Publishers; 1997.

9. Al-Muammar MN. Predictors of physicians' practices related to nutritional counseling and management in Riyadh City. Alexandria J Med 2012; 48:67-74.

10. WHO 2006. Available from: http://www.who.int/dietphysicalactivity/diet/ en/index.html. [Last accessed on $2011 \mathrm{Apr}$ 16].

11. WHO Media centre. Diabetes Factsheet No. 312. Available from: http:// www.who.int/diabetes/actionnow/en/mapdiabprev.pdf.[Last accessed on 2011 Apr 05].

How to cite this article: Sharma A, Pati S, Chakravarty N, Chauhan AS. Physicians' nutritional counselling practices: A study in district hospitals of Chhattisgarh. Int J Med Public Health 2013;3:103-6.

Source of Support: Nil, Conflict of Interest: None declared. 